\title{
Recommendations for Improving Photo Quality in Close Range Photogrammetry, Exemplified in Hand Bones of Chimpanzees and Gorillas
}

\author{
Recomendaciones para Mejorar la Calidad de las Fotos en Fotogrametría de Corto \\ Alcance, Ejemplificado en Huesos de las Manos de Chimpancés y Gorillas
}

\author{
Ana Bucchi ${ }^{1,2}$; Javier Luengo ${ }^{1,2}$; Ramón Fuentes ${ }^{3}$; Manuel Arellano-Villalón ${ }^{3}$ \& Carlos Lorenzo ${ }^{1,2}$
}

BUCCHI, A.; LUENGO, J.; FUENTES, R.; ARELLANO-VILLALÓN, M. \& LORENZO, C. Recommendations for improving photo quality in close range photogrammetry, exemplified in hand bones of chimpanzees and gorillas. Int. J. Morphol., 38(2):348-355, 2020.

SUMMARY: Photogrammetry is becoming increasingly popular in morphological research and teaching due to its portability, ability to reliably render 3D models, and quality-to-price relationship relative to some popular surface scanners. Compared to surface scanners, however, the learning process in photogrammetry can be very time consuming. Here we describe common mistakes of photo capture in close-range photogrammetry that greatly affect 3D output and tips to improve them. Problems were identified after the 3D model construction of 780 hand bones of chimpanzees and gorillas from museum collections. Their hands are composed of 27 bones which vary in length and complexity. We show how lighting, object position and orientation, camera angle, and background affect the 3D output. By taking these factors into account, time and error rates for beginners can be greatly reduced and 3D model quality can be considerably improved.

KEY WORDS: Close range photogrammetry; Proof of concept ; Primates; Hands.

\section{INTRODUCTION}

Photogrammetry is a technique for building threedimensional models of an object based upon photographs. It is growing in popularity in anthropology and related fields as it can produce high-quality and reliable virtual renderings of an object (Olson et al., 2013; Katz \& Friess, 2014; Evin et al., 2016). It is also cost-effective compared to some popular commercial surface scanners (Porter et al., 2016) and portable, which is convenient when researchers do not have access to other equipment.

Broadly, the photogrammetric process can be divided in two steps: image acquisition and image processing to obtain 3D models using software (the most popular software is Agisoft Photoscan, although there are open-source options available as well, such as VisualSFM and Multiview Environment [MVE]). Regarding the first point, photogrammetry requires a very specific kind of image, which has a tremendous impact on the $3 \mathrm{D}$ output. It is sometimes easier and more efficient to repeat the photo session than to try to build 3D models with poor-quality pictures. Specifications for image acquisition vary greatly depending on the preferences of the researcher, the conditions in which the object is set; for example if there is no electricity in the location where the object has been accessed, as in Porter et al., or if the object is static, as in Mitchell \& Chadwick (2008) or Mallison \& Wings (2014), and the characteristics of the object to be modeled (such as whether it is refractive or translucent (Nicolae et al., 2014; Porter et al.).

Our objects were relatively small, opaque, movable, and were rotated on a turntable inside a photocube to obtain the photos instead of being photographed using the walkaround method (Fig. 1). There are a handful of

\footnotetext{
${ }^{1}$ Institut Català de Paleoecologia Humana i Evolució Social (IPHES), Zona Educacional 4, Campus Sescelades URV, Tarragona, 43007, Spain.

${ }^{2}$ Universitat Rovira i Virgili (URV), Area de Prehistòria, Avinguda Catalunya 35, Tarragona, 43002, Spain.

${ }^{3}$ Department of Integral Dentistry, CICO-Research Centre in Dental Sciences, Dental School, Universidad de La Frontera, Chile.

Sources of fouding: This study was funded by the research projects AGAUR 2017 SGR 1040 and MINECO [PGC2018-093925-B-C32]. A.B. would like to acknowledge financial support from Becas Chile (Conicyt, Chile).
} 
recommendations in articles and webpages for photo capture regarding the types of objects to be photographed, although there is still a lack of comprehensive guidelines with examples to help beginners acquire photos that guarantee the scientific quality of the 3D models. This is important considering that most researchers are not experts in photography or photogrammetry.

We used photogrammetry (Fig. 1) to create 3D models from hand bones of African apes. Hands in the family Hominidae are composed of 27 bones that range from 1 to 10 centimeters long and have variable shapes, from small

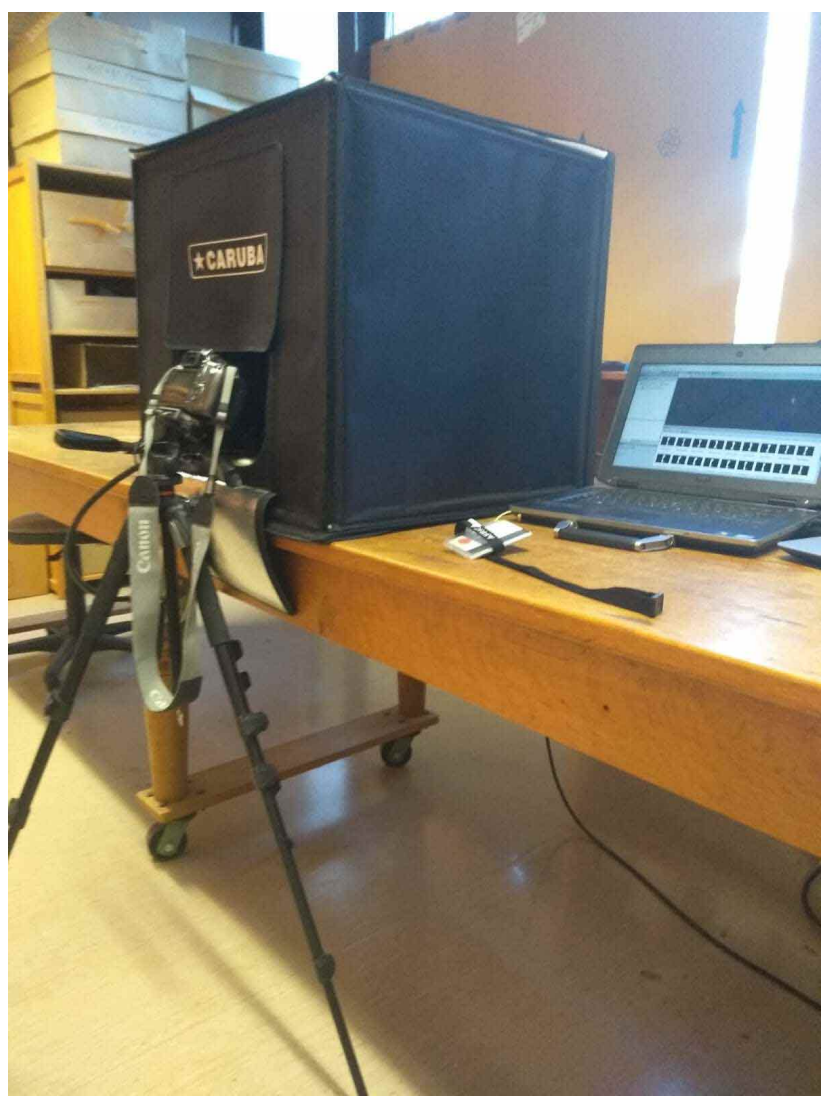

Fig. 1. Setup of the equipment.

Table I. Brand and price of the equipment.

\begin{tabular}{lll}
\hline Equipment & Brand and model & Cost (euros) \\
\hline Camera & Cannon EOS 1200D & 999 (includes len: \\
Remote control & RS-60 E3 & 19.84 \\
Tripod & AmazonBasics & 23.49 \\
Photo cube & Caruba LED 50x50x50 & 139.90 \\
Mastic & Blu-tack & 1.90 \\
Turntable & RamPro & 7.99 \\
Scale & Strati-Arqueolag & 3.24 \\
Total & & 1195.36 \\
\hline
\end{tabular}

and complex to long and simple. Hundreds of bones $(\mathrm{N}=780)$ were photographed in order to obtain 3D models, and several problems regarding image characteristics were addressed. In cases where no model or a poor-quality model was obtained from the photos, the photo sessions were redone, which allowed us to identify repetitive mistakes that resulted in higher quality models once solved. Considering the number of models, the equipment (Fig. 2, Table I) and photography instructions described below speed up the photo capture and the construction of the 3D model in the AgiSoft PhotoScan Professional Software (version 1.2.6).

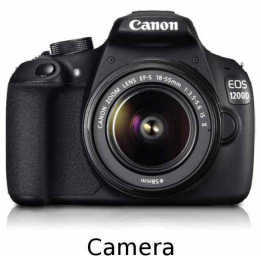

Camera

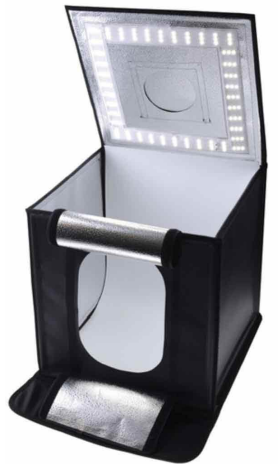

Photocube
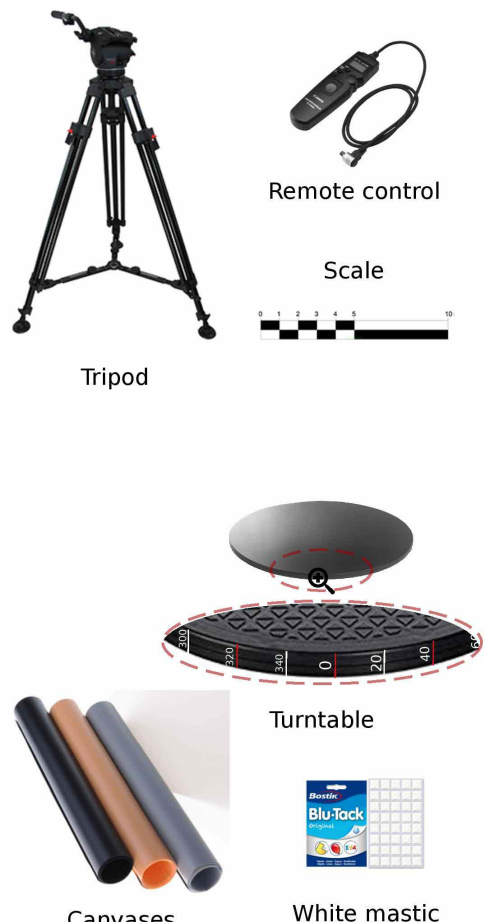

Fig. 2. Equipment used to take the photos.

\section{MATERIAL AND METHOD}

Materials and setup. Table I and Figures 1-2 show the equipment used here in the photo capture process. Hand bones were accessed from the primate collections of the Royal Museum for Central Africa, the Zoological State Collection in Munich, and the Zoological Museum in Barcelona.

We placed the phototube on a table, near an electrical outlet. The camera was connected to the remote control and mounted in a tripod (Fig. 1). The tripod and the remote control help prevent blurry images, and the remote control can be more comfortable for the operator when a large number of photos are taken. 
The photocube controlled the amount and evenness of the light on the object due to its reflective interior and the diffuse canvas; this is particularly important for complexly-shaped objects and when the photo capture is carried out in a poorly-lit place. One of the walls of the photocube (Table I) had small LED lights (the light source, which could be covered with a diffuser); three were reflective, and the remaining two were covered with a canvas. Because the canvas comprised the background in the final photo, we chose a color that contrasted with the bones (which was white in most cases).

The turntable was the same color as the background and was placed in the center of the cube. Marks were placed at 20-degree intervals on the side of the turntable, shown in Figure 2.

The bones were fixed to the turntable using a mastic the same color as the background and checked to ensure they remained fixed during rotation. Finally, we placed the scale next to the object.

Camera settings. Photos were taken with a Canon EOS $1200 \mathrm{D}$ camera mounted on a tripod. The lens was an EFS 18-55 mm macro 0.25/0.8ft and image size was $18 \mathrm{Mp}$. All the parameters were set to obtain the best quality photos and avoid different adverse situations which could
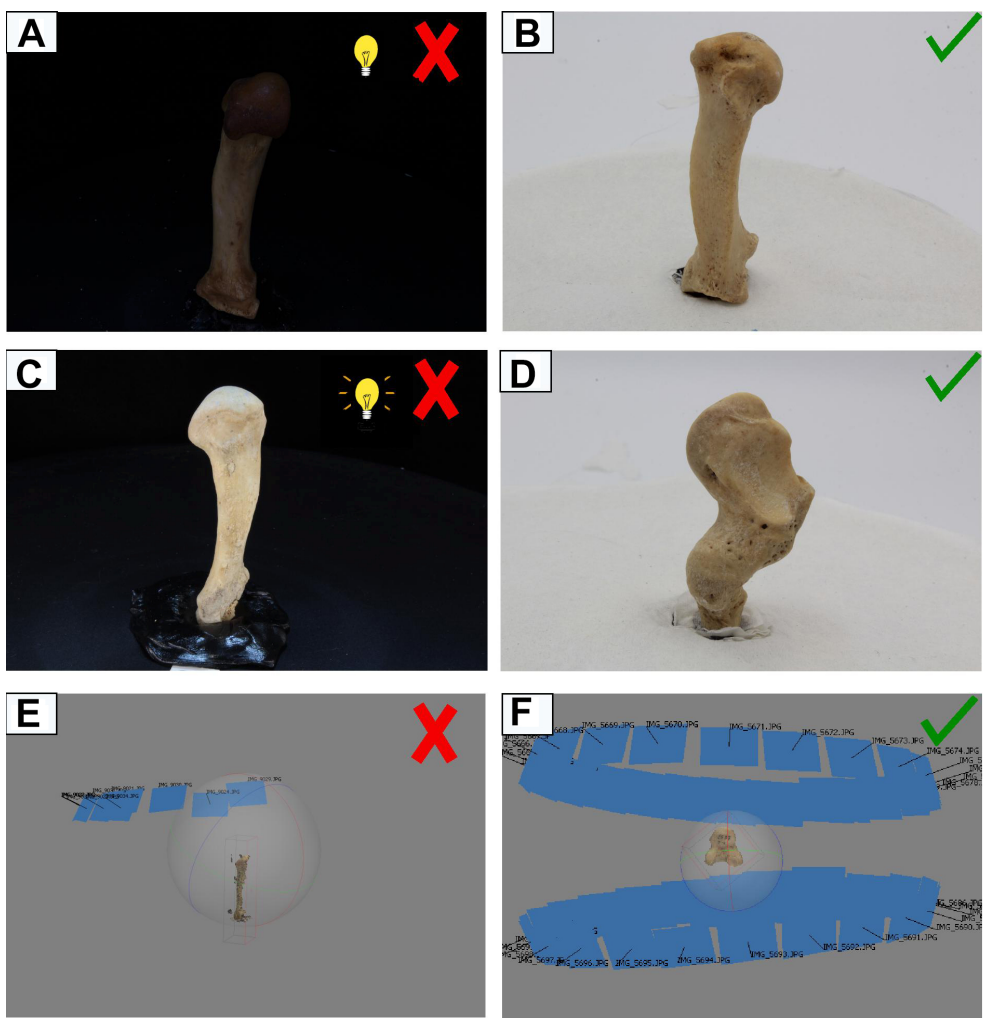

Fig. 3. Showing a dark (a) and over-exposed photo (c), while images b and $\mathrm{d}$ show adequately lit bones. Image e shows a dense cloud constructed incorrectly with overexposed photos; in most of these images (in which camera positions are represented by blue rectangles) there is not enough information to facilitate alignment and they cannot be used by the software to build the point cloud. In contrast, image $f$ shows a dense cloud constructed with all the photos. have affected the 3D output. High focal length was used (50-55 mm) to increase magnification of the object relative to the whole picture. Though borders can be affected by optic distortion when using high focal length, the details at the center of the image are sharper. We used a high Depth of Field (DoF) (f/29) to avoid blurriness. Similarly, the ISO was reduced to a minimum level of 100 to avoid grainy images. The shutter speed was not fixed, and varied depending on the object. Photos were captured within a distance of $25 \pm 10 \mathrm{~cm}$.

Images were saved in JPG format, which does not affect the quality of the final model (Mallison \& Wings) and occupies less disk space than uncompressed formats such as RAW.

\section{The photographic steps}

1. A photo of each bone's label was taken to facilitate identification of the final pool of photographs.

2. The object was placed in the center of the turntable and the scale next to it.

3. The turntable was placed with the zero-degree mark facing the camera.

4. The camera was positioned at an approximately 45-degree angle relative to the object (see Fig. 8h) so that the surface of the bone facing upwards could be captured in the photos. The angle should be such that there is no need to raise or lower the tripod to accommodate the different portions of the object being captured.

5. A photo was taken and checked to ensure it was correctly taken (see below).

6. The turntable was rotated every 20 degrees, until the zero-degree mark faced the camera again, resulting in 18 photos.

7. The bones were flipped 180 degrees so that the surface that had been facing the turntable was facing the upwards.

8. The scale was removed.

9. Pictures were taken every 20 degrees, until the zero-degree mark was facing the camera again. In total, 36 photos were taken of the bones.

\section{Photographic tips}

Amount of light: Too little or too much light can make the object look featureless (Figs. 3a,c), which can result in erroneous image alignment or even prevent alignment altogether (Fig. 3e, in 
contrast to Fig. 3f). Photogrammetry works by aligning common points photographed from at least two positions, so these reference points must be recognizable. Exposure time should be increased or decreased so the smallest surface details are visible (Figs. 3b,d).

Light distribution: Uneven lighting on the object can produce strong shadows on some parts of the bone (Figs. 4a,c,e). This is a problem when using a turntable; while rotating the object the shadows move as well, and complicate the alignment of photos in the software (e.g., Fig. $3 \mathrm{e}$ ), as explained in the first point. We used a photocube (Fig. 2, Table I) to ensure the bones were evenly lit and note that a white background produced better results than a black one.

Object relative to the background: The object should be easily distinguishable from the background and the background should be featureless and homogeneous (unlike Fig. 5a). A color that contrasts with the object should be chosen (not as in Figure 5b, but as in Figures $5 c$ and 5d). In our case, we used the canvases available in the photocube and white proved better than black, as it reflects light better and because some bones were labeled in back (Figs. 5a,b). The background were then removed along with the background in the masking step.

Mastic should be invisible in the photos (Fig. 6b) or it will complicate alignment (Figs. $6 a, e)$ and it will take more time to clean the model in the software. The mastic is used to fix the bone to the turntable. If the object remains still on its own, as the mandible shown in Figure $9 b$, it is not necessary to use mastic to affix it to the turntable.

When using the "moving around the object method" and using a single chunk in the software, as here, the background should be removed prior to the alignment of photos, which can be done by automatically masking the background in the Agisoft Photoscan Software, as shown in Figures $6 \mathrm{c}$ and $6 \mathrm{~d}$. This process takes around 2 minutes and allows the software to ignore the background in the subsequent steps. Other methods use the background to help with the alignment process and so it is not removed prior to alignment, but note that in this case two chunks must be used instead of a single one (see below).
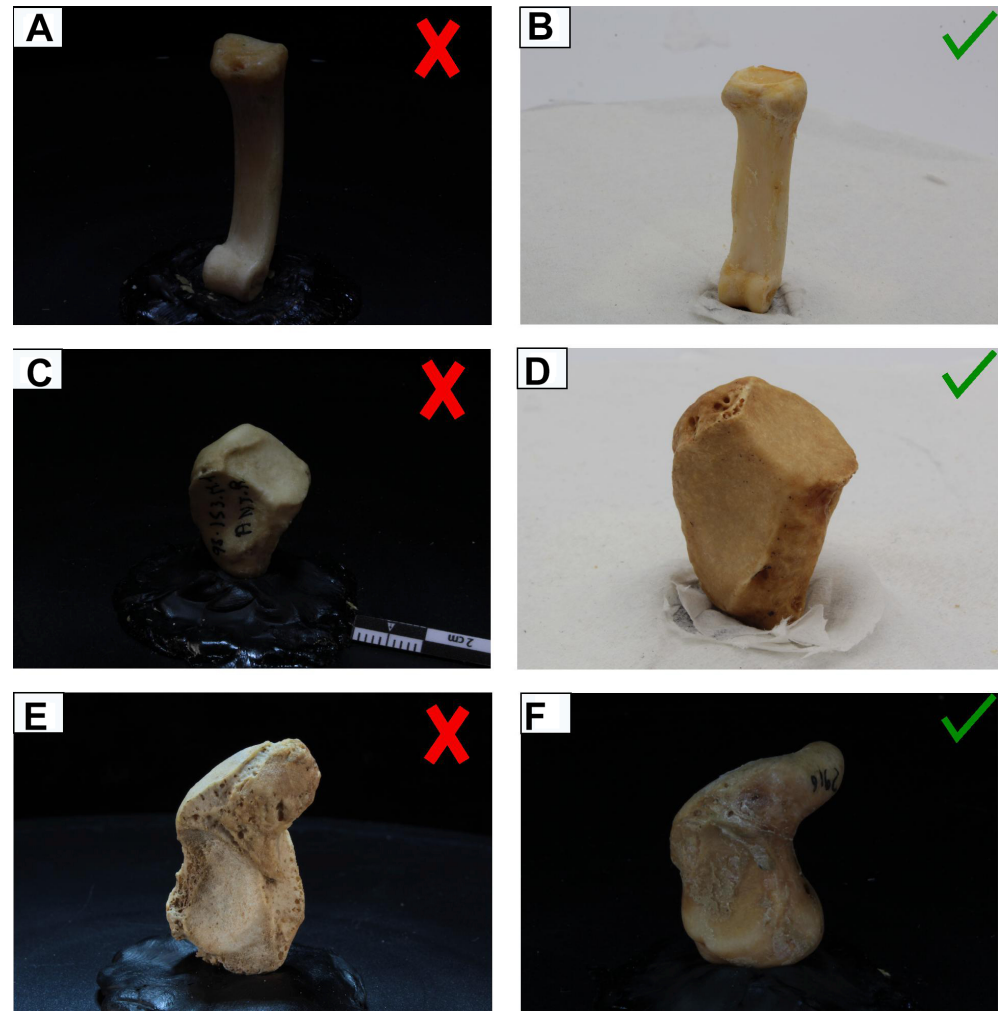

Fig. 4. Showing bone with harsh bone lightening (left column) and evenly lit (right column).
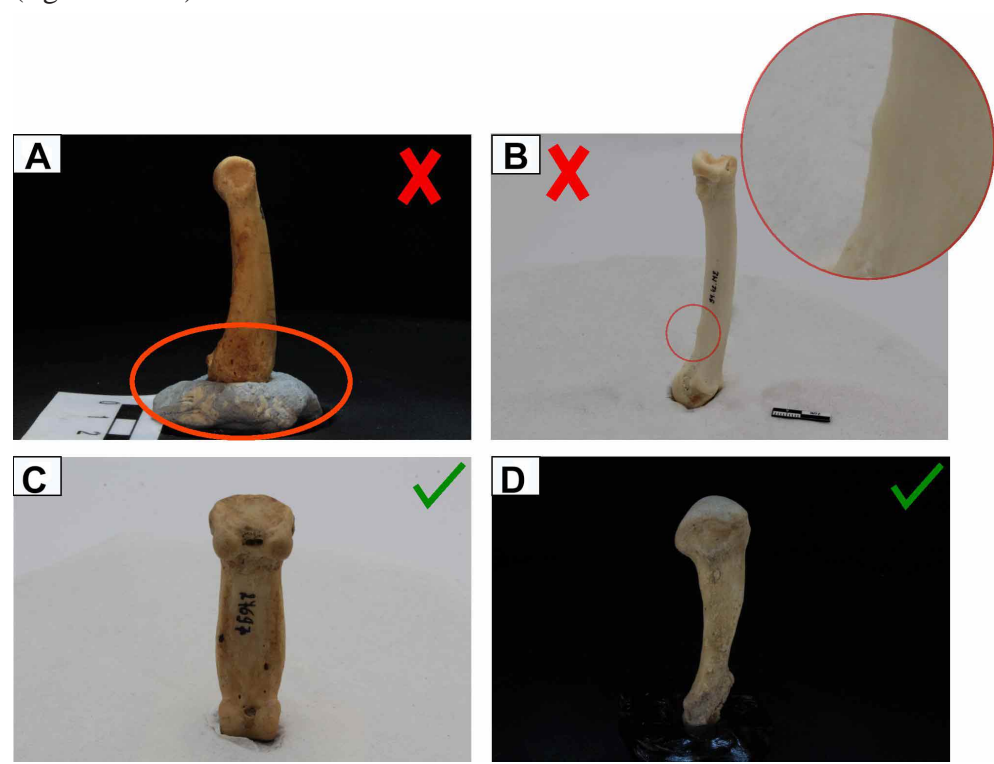

Fig. 5. The background. Image a is inadequate because the color of the mastic (light blue) is different from the background (black). Image b is inadequate because the bone is too white to use a background of the same color. Good contrast of the object relative to the background can be seen in images $\mathrm{c}$ and $\mathrm{d}$.

Frame the object so it occupies most of the photo. This will ensure the background occupies as little space in the picture as possible. In Figure $7 \mathrm{~b}$ the metacarpal is position vertically relative to the screen, but 
the camera can also be turned 90 degrees so that the long axis of the bone matches the long axis of the screen (Fig. 7d). This is preferable to flipping the bone, because then a larger part of the bone will not be visible in the photos (Fig. 7c). Note that the difference between Figures $7 \mathrm{c}$ and $7 \mathrm{~d}$ is that in $\mathrm{c}$ the long axis of the bone is facing the turntable while in $7 \mathrm{~d}$ it is not.

Camera lenses can be configured at a specific distance from the camera to control the magnification of the object and how much of the environment is going to be captured. Here we used a relatively long focal length $(55 \mathrm{~mm})$ so the object looks big relative to the whole picture. This work well with phalanges and metacarpals, but note that small bones, such as some carpals (trapezoid, triquetral, and lunate, 1.5 to $3.5 \mathrm{~cm}$ ), occupy a smaller area relative to the whole image regardless.

Focus: The focus of the object should be as sharp as possible (Fig. 8b).

Use a tripod and a remote control (Table I) or the exposure-delay mode of the camera to prevent blurry images (Fig. 8a).

A high depth of field (f/29) was used to ensure that as much of the object got into proper focus.

In order for the object to remain in focus throughout the photo session, it must be facing the center of the camera screen (Fig. 8d) and be in the center of the turntable (Fig. 8f). Otherwise it will be out of focus during part or all of the photo session.

Avoid sharp angles of the object relative to the camera, as in Figure 8g. Otherwise the inferior part of the bone will remain out of focus. In this case the tripod should be lowered.

Check the position of the object relative to the vertical axis of the screen. Put the longer axis of the object as straight and close to the vertical axis of the screen as possible (Fig. 8f). The metacarpal in Figure $8 \mathrm{i}$ is inclined and the base of the bone (which is facing upwards) remains out of focus when rotating the turntable.

Scale: Place the scale near the object as in Figure 9a and take it out in step 8 (Section The photographic steps). This way half of the photos are taken with the scale and the other half without it. As such, all pictures can be put in the Agisoft Photoscan software in a single
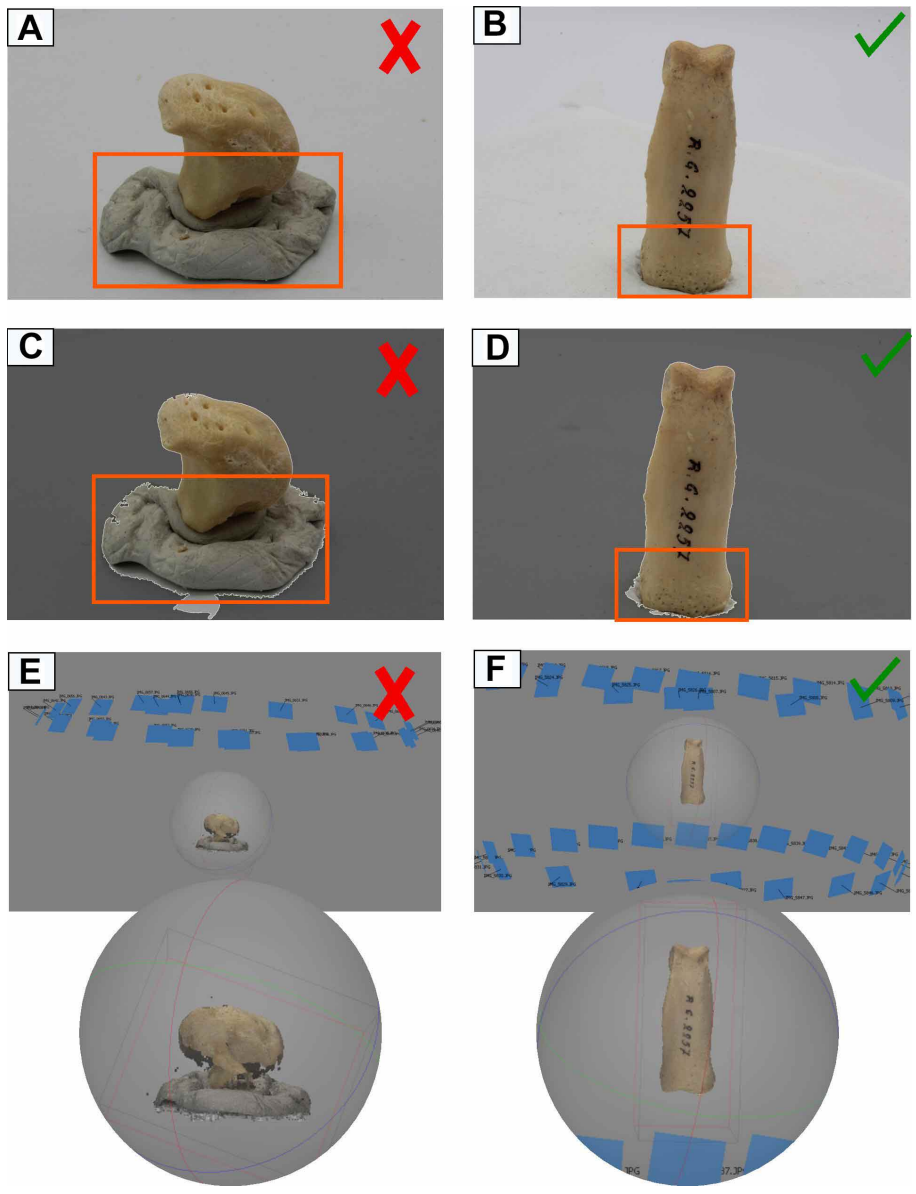

Fig. 6. The effect of the visible (a) and hidden mastic (b) in the alignment of the photos when using a single chunk in the software. If it is visible, mastic may not be masked (c) and instead might be used by the software for alignment rather than the bone, resulting in a wrong dense cloud as shown in image e. In contrast, if the mastic is not visible, the masking step is more efficient (d) and so is the alignment of photos.
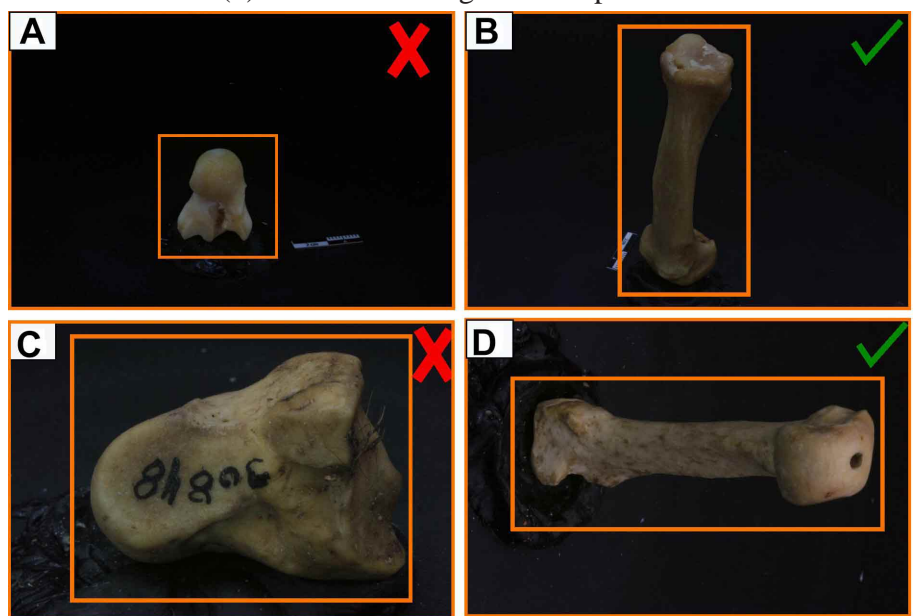

Fig. 7. Size of the bone relative to the whole picture. The camera is far from the object in image a, making it look small, while in image c most of the bone is facing the turntable. Images $\mathrm{b}$ and $\mathrm{d}$ are correctly framed bones. In $\mathrm{d}$ the camera is turned in 90 degrees. 

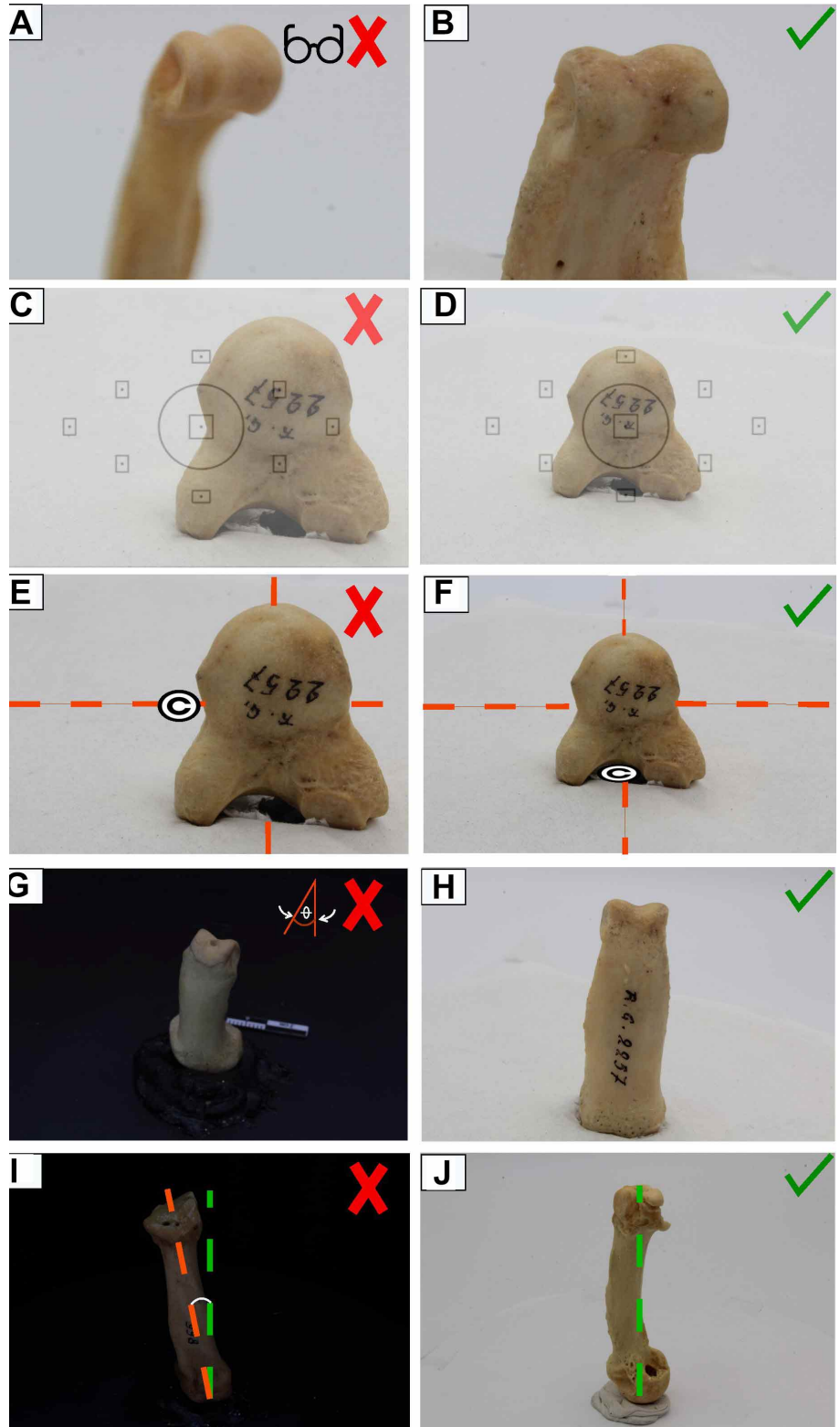

Fig. 8. Factors affecting focus. Image a: bone is blurry because the turntable was rotated too quickly. Using a tripod and delaying photo capture once the shutter is pressed prevents blurry images. Image b: sharp image. Image c: bone far from the center of the camera screen. Image d: bone facing the center of the camera screen. Image e: a bone located far from the center of the turntable. Image $\mathrm{f}$ : bone in the center of the turntable. Image g: sharp angle of the camera relative to the bone. Image $\mathrm{h}$ : correct angle between the bone and the camera. Image i: inclined metacarpal. Image j: straight metacarpal.

chunk, which speeds up the process of 3D model creation. If the scale is in every photo (Fig. 9b), two chunks will be needed, which will add a step in the model creation process (alignment of the chunks). If only one chunk is used the software may align the photos by the scale and not by the bone, which occurred with the mastic in Figure 6e. A scale such as the one used by Porter et al. can also be used to help align the photos (Fig. 9b). Another option is not to use scale at all (Fig. 9c) and scale the model by using a known length of the bone (as in Fig. 10).

Number of photos: Every area of the bones must be visible in at least two photos (Fig. 10) so the software can identify reference points. A high percentage of overlap (70-80 \%) is needed in all photos. Take more photos than are strictly necessary. Here 30 photos were generally enough to build most of the models, but because some bones have more homogeneous textures or some photos were taken incorrectly, 36 photosand in some cases more-were taken to ensure a successful 3D model. When deciding on the number of photos to take, it should be taken into account that that the number of photos affects the time required by the software to build the 3D models, as the more photos there are the slower the model is built.

\section{RESULTS AND DISCUSSION}

The Table II shows parameters describing the quality of some of the 3D models constructed here. They were obtained from the photographs captured following the recommendations described below. Four bones were chosen for this purpose; a small, simple one (trapezoid of chimpanzees), a medium-sized complex one (scaphoid), a medium-sized simple one (third proximal phalanx), and a long relatively complex one (third metacarpal). The mean maximum lengths of the bones were also calculated to indicate their size.

Initially, a large number of errors (poorly constructed models or failure to build models at all) occurred. The repetition of photo session this time fixing the aspects described in this paper greatly improve model quality, the probability of success (in here, in 6 of the 780 cases failed to construct a 3D model after the second attempt) and the time needed to build the model in the software. Figures 11 and 12 show two 3D models, one from a carpal bone (gorilla), and the other from a fourth metacarpal (chimpanzee). These 3D models are avaliable upon request.

It should be noted that after this second attempt the 3D model included holes in a few cases. We believe this is due to the very smooth texture of some bones, especially in the joint areas. The guidelines described here did not fix this problem. Previous studies have tested dusting featureless surfaces of 

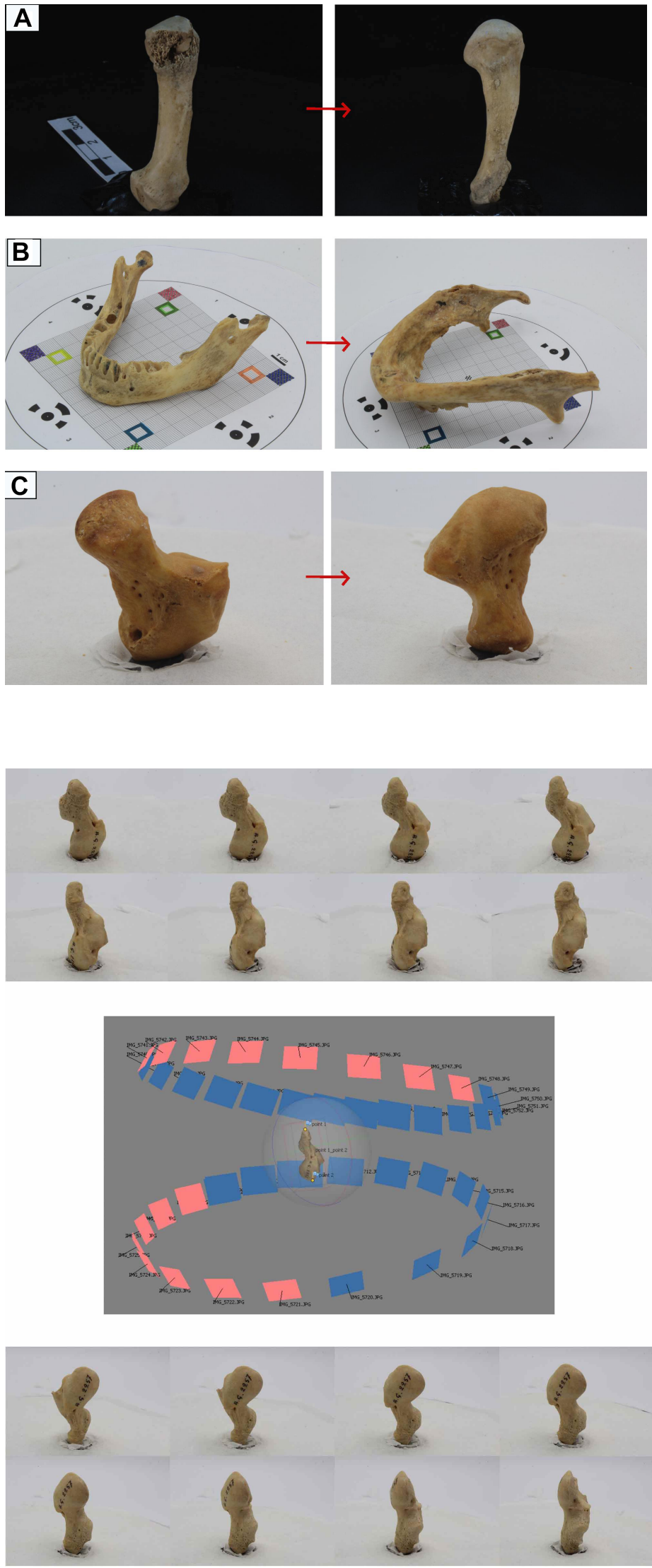

Fig. 9. Scale in the photo session. Image a represents the same photo session in which the scale was placed (left), and then removed once the bone was flipped (right) (one chunk method). Image b shows a photogrammetric scale that helps with the alignment and scale of the models (two chunk method), similar to the one that can be accessed in Porter et al. Image c shows a photo session in which no scale was used (one chunk method).

archaeological material with powder (Porter et al.) or using textured light pattern projections (Galantucci et al., 2008; Koutsoudis et al., 2015; Santoši et al., 2019) to increase alignment and dense reconstruction quality, but this was not tested here.

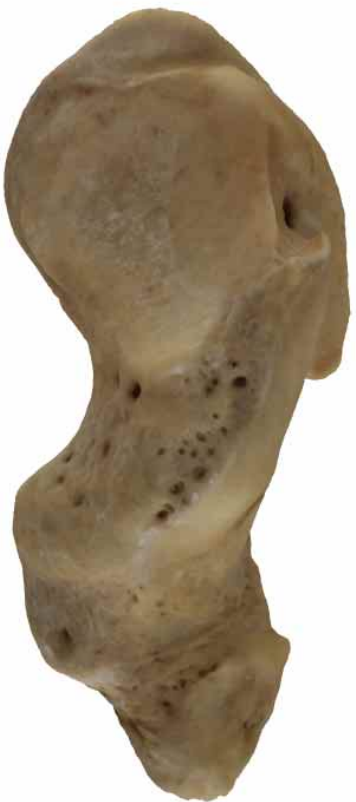

Fig. 11. 3D model of a scaphoid from a male gorilla (Gorilla beringei beringei) held at the Royal Museum of Central Afritriangles: 519.480 . Number of photos: 46. ca (Tervuren). Number of

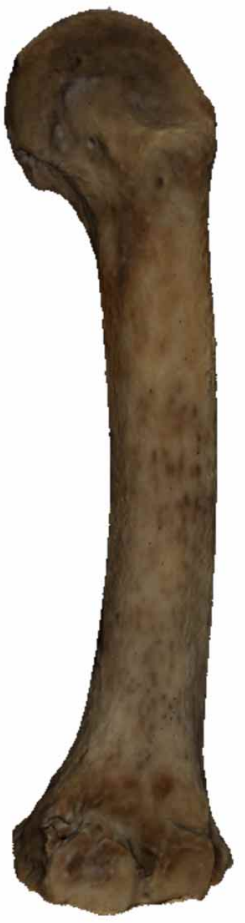

Fig. 12. 3D model for a fourth metacarpal of a chimpanzee held at the Royal Museum of Central Africa (Tervuren). Number of triangles: 279.024. Number of Photos: 30.
Fig. 10. A 3D model of a scaphoid from a gorilla (central image) in Agisoft Photoscan software. Top photos were taken approximately every 20 degrees, and the position of the camera for each photo is highlighted in pink at the top of the central image. Bottom photos were taken when the bone was flipped and the position of the camera for each photo is shown in pink at the bottom of the central image. 
Table II. Parameters describing the quality of the 3D models of four hand bones obtained with the method described in the text. Triangles are of uniform size.

\begin{tabular}{|c|c|c|c|c|c|}
\hline Bone & Taxon & $\begin{array}{l}\text { Number of } 3 \mathrm{D} \\
\text { models }\end{array}$ & $\begin{array}{c}\text { Mean number of } \\
\text { triangles }\end{array}$ & $\begin{array}{l}\text { Standard } \\
\text { deviation }\end{array}$ & $\begin{array}{l}\text { Mean maximum } \\
\text { length }(\mathrm{cm})\end{array}$ \\
\hline Trapezoid & Chimpanzee & 10 & 230.387 & 64.553 & 1.88 \\
\hline Scaphoid & Gorilla & 22 & 562.250 & 137.420 & 3.97 \\
\hline Third metac arpa 1 & Gorilla & 18 & 370.590 & 130.331 & 7.99 \\
\hline Third proximal phalanx & Chimpanzee & 26 & 438.542 & 161.908 & 5.59 \\
\hline
\end{tabular}

\section{CONCLUSIONS}

Here were describe simple, effective criteria to facilitate taking good photos in close-range photogrammetry using relatively small, opaque objects such as the hand bones of African apes. We think these recommendations are also appropriate for a variety of objects that might fit in a photocube (except objects with difficult optical properties, such as brightness or transparency). With few exceptions, 3D models constructed following these guidelines are high quality and appropriate for scientific purposes.

\section{ACKNOWLEDGEMENTS}

We are grateful to the institutions holding the material we analyzed; the Royal Museum for Central (Belgium), Museu de Ciències Naturals de Barcelona (Spain) and Zoologische Staatssammlung München (Germany), and to the people who kindly helped us there, especially to Emmanuel Gilissen, Javier Quesada, Anneke van Heteren and Michael Hiermeier. To Juan Ignacio Morales and Antonietta Del Bove for their photogrammetric guidelines.

BUCCHI, A.; LUENGO, J.; FUENTES, R.; ARELLANOVILLALÓN, M. \& LORENZO, C. Recomendaciones para mejorar la calidad de las fotos en fotogrametría de corto alcance, ejemplificado en huesos de las manos de chimpancés y gorillas. Int. J. Morphol., 38(2):348-355, 2019.

RESUMEN: La fotogrametría está siendo cada vez más popular en la investigación y enseñanza morfológica. Esto debido a su portabilidad, confiabilidad de los modelos 3D y buena relación calidadprecio. Comparada con los escáneres de superficie, sin embargo, el proceso de aprendizaje de la fotogrametría puede llevar mucho tiempo. Aquí se describen errores comunes en la toma de fotos para fotogrametería que afectan de manera importante la creación de los modelos 3D, así como consejos para superarlos. Los problemas descritos fueron identificados luego de la construcción de 780 modelos 3D de huesos de la mano de chimpancés y gorillas depositados en distintas colecciones de museos. Las manos de estas especies están compuestas por 27 huesos que varían en tamaño y complejidad. En este artículo mostramos como la luz, la posición y orientación del objeto, el ángulo de la cámara y el fondo de la imagen afectan el resultado en 3D. Consi- derando estos factores, personas que están aprendiendo esta técnica pueden reducir de manera importante el tiempo y la probabilidad de error, y mejorar considerablemente la calidad de los modelos 3D.

PALABRAS CLAVE: Fotogrametría de corto alcance; Prueba de concepto; Primates; Manos.

\section{REFERENCES}

Evin, A.; Souter, T.; Hulme-Beaman, A.; Ameen, C.; Allen, R.; Viacava, P.; Larson, G.; Cucchi, T. \& Dobney, K. The use of close-range photogrammetry in zooarchaeology: Creating accurate 3D models of wolf crania to study dog domestication. J. Archaeol. Sci. Rep., 9:87-93, 2016.

Galantucci, L. M.; Percoco, G. \& Dal Maso, U. Coded targets and hybrid grids for photogrammetric 3D digitisation of human faces. Virtual Phys. Prototyp., 3(3):167-76, 2008.

Katz, D. \& Friess, M. Technical note: 3D from standard digital photography of human crania - A preliminary assessment. Am. J. Phys. Anthropol., 154(1):152-8, 2014.

Koutsoudis, A.; Ioannakis, G.; Vidmar, B.; Arnaoutoglou, F. \& Chamzas, C. Using noise function-based patterns to enhance photogrammetric 3D reconstruction performance of featureless surfaces. J. Cult. Herit., 16(5):664-70, 2015.

Mallison, H. \& Wings, O. Photogrammetry in paleontology - a practical guide. $J$. Paleontol. Tech., 12:1-31, 2014.

Micheletti, N.; Lane, S. N. \& Chandler, J. H. Application of archival aerial photogrammetry to quantify climate forcing of alpine landscapes. Photogramm. Rec., 30(150):143-65, 2015.

Mitchell, H. L. \& Chadwick, R. G. Challenges of photogrammetric intra-oral tooth measurement. Int. Arch. Photogramm. Remote Sens. Spat. Inf. Sci., 37 Part B5:779-82, 2008.

Nicolae, C.; Nocerino, E.; Menna, F. \& Remondino, F. Photogrammetry applied to problematic artefacts. Int. Arch. Photogramm. Remote Sens. Spat. Inf. Sci., 40:451-6, 2014.

Olson, B. R.; Placchetti, R. A.; Quartermaine, J. \& Killebrew, A. E. The Tel Akko total archaeology project (Akko, Israel): Assessing the suitability of multi-scale 3d field recording in archaeology. J. Field Archaeol., 38(3):244-62, 2013.

Porter, S. T.; Roussel, M. \& Soressi, M. A Simple Photogrammetry Rig for the Reliable Creation of 3D Artifact Models in the Field: Lithic Examples from the Early Upper Paleolithic Sequence of Les Cottés (France). Adv. Archaeol. Pract., 4(1):71-86, 2016.

Santosi, Z.; Budak, I.; Sokac, M.; Puskar, T.; Vukelic, \& Trifkovic, B. 3D digitization of featureless dental models using close range photogrammetry aided by noise based patterns. Facta Univ. Ser. Mech. Eng., 16(3):297-305, 2019.

Tiano, P.; Tapete, D.; Matteini, M. \& Ceccaroni, F. The Microphotogrammetry: A New Diagnostic Tool for On Site Monitoring of Monumental Surfaces. Florence, Proceedings of the International Workshop SMW08, 2008. pp.27-9.

\section{Corresponding author:}

Ana Bucchi

4 Zona Educacional

Campus Sescelades URV

43007 Tarragona - SPAIN

Received: 24-07-2019

Accepted: $15-10-2019$

Email: anabuchi@gmail.com 